\title{
Harmonics of Double-fed Wind Power System with Grid-Tied Dual-PWM Converter
}

\author{
Qiaoli He \\ Inner Mongolia Vocational College of Chemical Engineering, Huhhot, 010070, China \\ *Corresponding Author Email: qiaolihe81921@126.com
}

Received: April 17, 2020. Revised: October 23, 2020. Accepted: October 26, 2020. Published: October 26, 2020.

\begin{abstract}
To fill the gaps of the double-fed wind power system, this paper conducts a study for the scarcity and integration of social resources. The $\mathbf{L F}$ harmonics on the DC and grid sides are surveyed based on the double Fourier transform algorithm, in conjunction with the power balance theory. A study model has also been built herein. The findings show that the calculated values of the HF harmonic components in the DFIG rotor current almost coincide with the simulation results, regardless of whether the wind velocity is $7 \mathrm{~m} / \mathrm{s}$ or $19 \mathrm{~m} / \mathrm{s}$. When the three-phase voltage of the grid is unbalanced, the stator current contains the grid side basebands with LF harmonics of odd times, among which, the fundamental frequency of triple grid side baseband is the most distinct. It is thus clear that the simulation can capture relevant voltage and current data for the wind power system running in the balance and unbalanced states of grid voltages. it is therefore proved that the theoretical analysis is accurate and reliable.
\end{abstract}

Keywords - Double-fed Wind Power System, Grid-Tied Dual-PWM Converter

\section{INTRODUCTION}

With a vast territory, China's energy resources are distributed everywhere but unevenly. As fossil energy has been nearly depleted, domestic wind power plants come into service intend to promote the sustainable development of human society. The double-fed induction generator, a kind of wound-rotor induction motor, as an important part of the energy conversion system, has been widely used in real life. The harmonic problem is fundamental to the energy of the double-fed wind power system. Many scholars at home and abroad have made extensive studies on this problem. Based on the power balance theory, this paper traces the LF harmonics on DC and grid sides using the double Fourier transform algorithm. A study model is also built herein.

\section{ITERATURE REVIEW}

Liu et al. proposed an exact analytical expression for harmonic calculation of doubly fed induction fans. The proposed model fully considered the interaction of harmonics in stator current, rotor current $\mathrm{W}$ and mechanical torque, and was still applicable in the case of faults [1]. Ji et al. studied the parallel resonance phenomenon caused by the output current and voltage of the wind turbine and the impedance of the wind farm, gave the analytic expression of resonance, and analyzed the influence of short-circuit power and wind farm parameters on resonance, so as to prevent resonance phenomenon by setting reasonable parameters of the wind farm [2]. Behnia et al. proposed a control strategy using quasi-proportional resonant controller to suppress the negative sequence current component and harmonic current component of grid-connected. This strategy not only effectively suppressed the negative sequence component of grid-connected current caused by unbalanced grid voltage, but also suppressed the low-order harmonic current component introduced by grid voltage or power generation system [3-4]. Zhu et al. analyzed and calculated the harmonics of three-phase rectifier-single-phase inverter used in traction power supply system, discussed the process of space vector pulse width modulation rectifier and sine-wave pulse-width modulation inverter, respectively, and obtained the specific harmonic frequency. It has certain reference value for deducing the harmonic generation mechanism of three-phase inverters used in wind power system [5]. Sathiyanarayanan and Kumar put forward an eight-switch converter. Compared with the traditional 12 -switch converter, it reduced the number of switching devices, and better controlled the direct current bus 
voltage by feedback and feed-forward compensation to compensate harmonic and voltage sag. However, this research was still in the stage of research and development of topology structure and had not been really applied in wind power system [6-8]. Serhoud and Benattous put forward the idea of separating positive and negative sequence currents and voltage vectors under asymmetric voltage faults by using periodic signal delay method with the control objective of restraining active power fluctuation of converters. Then, according to the positive and negative sequence model, the gate controller was used to control the corresponding variables. This method had the problem of time delay when extracting the positive and negative sequence components. Therefore, only when the asymmetry $=$ phase voltage steady-state operation, the effect was more obvious. In addition, the use of this control strategy would affect the dynamics of wind turbine control system [9].

Zongze et al. studied a doubly-fed fan integrated with active filter device and proposed a new control algorithm. By using indirect current control, the grid-side converter had the function of harmonic compensation. The rotor-side converter could compensate the reactive power of load [10]. Wang and Lin deduced and analyzed the harmonic characteristics of single-phase two-level voltage rectifier in detail. Although only the harmonics of single-phase rectifier were deduced, the theory of power balance of converter used by Wang and Lin still had important reference significance for the study of harmonics of S-phase rectifier [11-12]. Pichan et al. proposed a new control strategy of machine-side converter for stator current containing a large number of harmonics in permanent magnet motor. By controlling stator current in rotor synchronous rotating coordinate system, the specified number of harmonics could be suppressed [13]. Bekakra and Attous proposed to use notch filter method to obtain positive and negative sequence electric quantity, and then used double PI and current loop to control positive and negative sequence electric quantity respectively to maintain the control target of active power fluctuation. However, the extraction of positive and negative sequence voltage and current in double current loop needed a second-order notch filter, which would delay the control performance. And the reduction of stability margin would affect the control accuracy [14]. In the same year, Bekakra and Attous proposed PR control strategy of dual pulse width modulation (PWM) converter based on the mathematical model of power converter and generator in doubly fed wind power generation system and the characteristics of proportional resonant (PR) controller. This method made full use of the advantage that PR controller could control alternating current input signal without static error in static coordinate system. Active current and reactive current components under vector control strategy were converted into static coordinate system for adjustment, and the control tasks and dual functions of maintaining direct current voltage stability and adjusting power factor of grid-side converter were realized. Compared with the traditional double closed-loop PI control, the decoupling control of active and reactive power of the feeder motor did not need complicated coordinate rotation transformation and did not have coupling term and feed-forward compensation term affected by temperature and circuit parameters. Moreover, it was easy to realize the compensation of low-order harmonic current of the system, and it reduced the difficulty of the control algorithm implementation and improved the robustness of the control system and the performance of the control algorithm [15-16]. Saad et al. took maintaining the constant bus voltage of DFIG grid-side converter as the control objective, and then calculated the given instruction of double current loop but did not suppress the reactive power fluctuation of grid-side converter and this strategy had some limitations [17].

In conclusion, the above-mentioned experts and scholars have little research on the harmonic generation mechanism of the rectifier inverters used in wind power, especially the back-to-back dual PWM converters in doubly-fed wind power systems. At the same time, the harmonic generation and transmission by converters in wind power systems are also inadequate, so it is necessary to establish a specific harmonic research system. Therefore, based on the above research status, combining with the power balance theory, the double Fourier transform algorithm is used, the direct current side and the grid side low frequency harmonics are studied, and the research model is established.

\section{PRINCIPLE AND METHOD}

The grid-connected principle of DIFG is: for a Doubly Fed Induction Generator (DFIG), the stator is connected to the transformer, and the rotor to a back-to-back, three-phase two-level voltage type dual-PWMAC-DC converter. The converter will generate and propagate harmonics when achieving the frequency conversion process, so that there is a certain harmonic component in 
the rotor and stator currents. As shown in Fig. 1, it is a back-to-back three-phase two-level converter used in a doubly fed wind power system, where $\mathrm{S}$ is a switch device. The grid-side converter control adopts voltage-current double closed loop control, which can allow the DFIG to realize the rectification operation of the unit power factor in the sub-synchronous state and the inverter operation of it in the super-synchronous state. As the controllable power factor is 1 during normal operation of the DIFG, the back-to-back dual-PWM converter is superior to other topological converters to a certain extent. The rotor side converter is joined to the DIFG's rotor, and its controller integrates the vector control of the DFIG, so that it determines how well the performance of the whole doubly fed wind power system is. In order to implement the decoupling of the active and reactive components in the rotor current, the $\mathrm{dq}$ decoupling controller is required to make sure the DFIG can achieve the maximum power tracking operation.

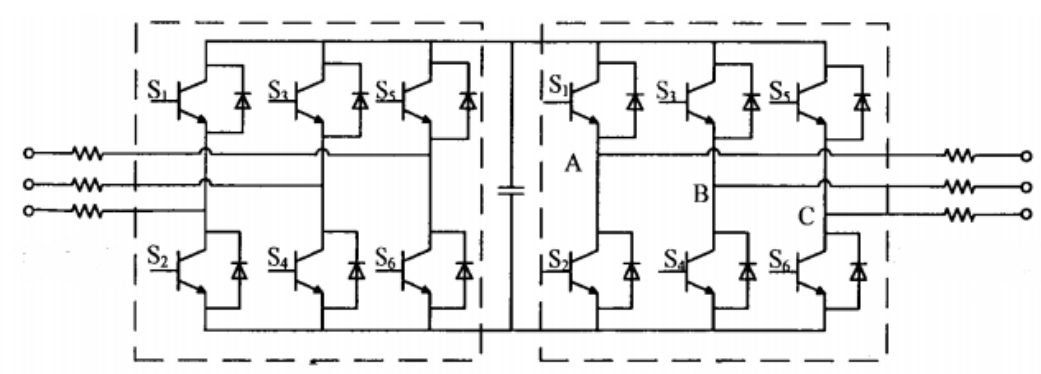

Fig. 1 Back-to-back dual PWM converter topology

The pulse modulation is the core of the converter principle, and also the root cause of why the converter as a power electronic component generates the harmonic. The principle of pulse modulation technology is to generate control pulses, and what harmonics are produced may be subjected to different modulation methods. The basic principle of sinusoidal pulse width modulation is that a sinusoidal modulating wave is compared with a triangular carrier to generate positive and negative level square wave signals with different pulse widths. Doubly-fed wind power system usually adopts the Bi-polar SPWM modulation. As shown in Fig. 2 , the SPWM modulation principle is given for the A-phase in the three-phase voltage. When the modulation wave amplitude is greater than the carrier value, a positive level generates, otherwise, there is a negative level. Square waves with different duty cycles are output to acquire different output voltages.

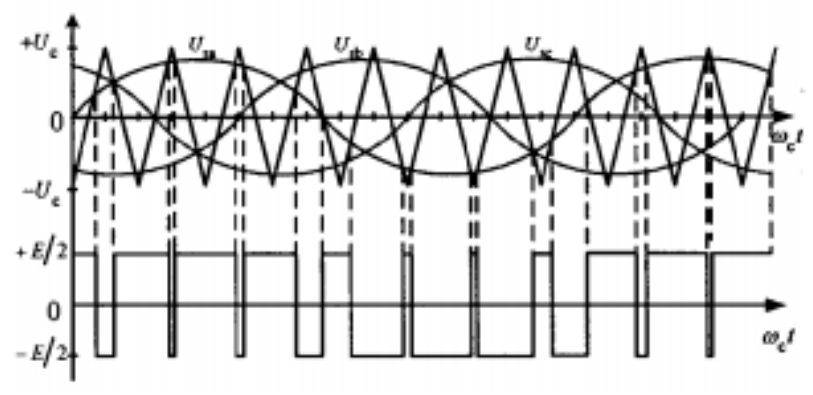

Fig. 2 SPWM modulation principle and A phase modulation waveform 
Assume that there is no harmonic in the current on the grid side, so does in the DC capacitor voltage. The higher harmonic of the rotor current is mainly generated by the inverter process of the dual PWM converter. Take the phase A voltage as an example, the harmonics in the inverter process are modeled.

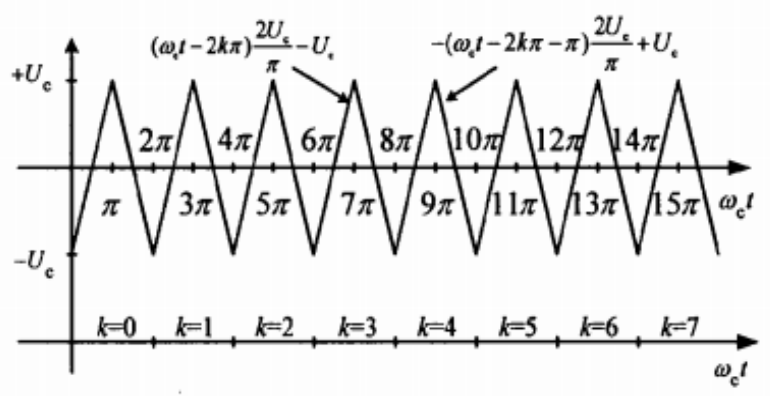

Fig. 3 Piecewise linear function of a triangular carrier

The carrier is represented by two piecewise functions according to Fig. 3. The triangular carrier can be expressed as:

$$
u_{c}\left\{\begin{array}{lc}
-\left(w_{c} t-2 k \pi\right) \frac{2 U}{\pi}+U_{c} & 2 k \pi+\pi \leq w_{c} t \leq 2 k \pi+2 \pi \\
\left(w_{c} t-2 k \pi\right) \frac{2 U_{c}}{\pi}-U_{c} & 2 k \pi \leq w_{c} t \leq 2 k \pi+2 \pi
\end{array}\right.
$$

When the function $\mathrm{f}(\mathrm{t})$ has more than one variable st, but is determined by two variables, that is to say, when the function becomes $\mathrm{f}(\mathrm{X}, \mathrm{Y})$, it is required to obtain the Fourier series by two Fourier transforms. This is the double Fourier transform. The coefficient of the double Fourier series satisfies the following relational expression:

$$
A_{m n}+j B_{m n}=-\frac{1}{2 \pi^{2}} \int_{-\pi}^{\pi} \int_{-\pi}^{\pi} u_{2 a} e^{j(m x+n y)} d X d Y
$$

For the modeling and simulation of wind power systems, in the earlier study, most scholars applied offline simulation technology. When the offline simulation software runs, the system solution speed depends on the existing computing speed and the complexity of the mathematical model for the system. For system with switch devices, offline simulation runsat an extremely slow rate and does not simulate its dynamic properties well. In this case, offline simulation is not applicable to simulate power converters with high switching frequencies. As the dual PWM converter used in the doublyfed wind power system includes many switch devices and needs to simulate a higher switching frequency, the offline simulation technology cannot well simulate its working mode. Therefore, real-time online simulation of the doublyfed wind power system should be implemented with important data, which proyide the clues to the general offline simulation.

This study applies a real-time data simulator (RTDS) to simulate the doublyfed wind power system, thus achieving harmonic data acquisition. As a new type of simulation tool, the RTDS focuses on realizing the electromagnetic transients of power systems. Unlike the simulation mode of offline software in the ideal state, the RTDS can accurately simulate the dynamic behaviors of the whole power system. It has a good compatibility and scalability. The graphical interface between the RTDS hardware and the users is implemented by the (2) puilt-in RSCAD with different functional modules, which can built simulation circuits, model operation and simple data analysis.

The main interface of the doublyfed wind power system built in RSCAD herein is shown in Fig. 4, where, the left WTG1 box is a small time step module. Some major components for the wind power system, including DFIG, are modeled under small time step condition. 


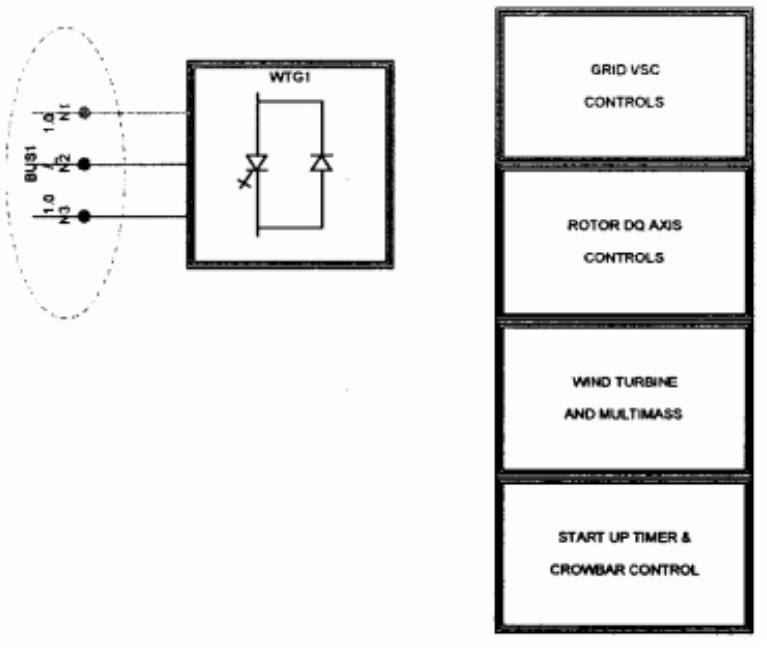

Fig. 4 Main interface of the dual-fed fan model

The interface transformer includes three single-phase interface transformers, which functions to connect large-step and small-step networks. On the high-voltage side, the voltage is set to $127.01 \mathrm{kV}$ in line with the $220 \mathrm{kV}$ voltage grade of the external power grid; on the low-voltage side, it is set to $22 \mathrm{kV}$, to connect the high-voltage side of the three-winding transformer. In addition, in Runtime, the voltage, current, active power, and reactive power of the corresponding nodes can be

\section{RESULTS AND ANALYSIS}

As shown in Table 1, under the conditions that the three-phase voltage of grid is unbalance, the wind speed is $7 \mathrm{~m} / \mathrm{s}$ and $19 \mathrm{~m} / \mathrm{s}$, that is, when the DFIG works in the sub-synchronous and super-synchronous states, the calculated and simulated values of the DC side voltage harmonic component are compared. It is known from Table 1 that the two values are almost identical, regardless of whether the DFIG operates in the sub-synchronous state or super-synchronous state. It is thus proved that the DC-side voltage harmonic analysis as timely supervised. The high-voltage side of the three-phase three-winding transformer is connected to the interface transformer, and the rated voltage is set to be consistent with that of the interface transformer; the other two windings are connected with the DFIG stator side of DFIG and back-to-back dual-PWM voltage source converter, and the rated voltage is set to that of the stator. The three-phase three-winding transformer is joined as a star

type.

described in Chapter 3is correct. When the three-phase voltage of the grid is not balanced, the wind speed is $7 \mathrm{~m} / \mathrm{s}$ and $19 \mathrm{~m} / \mathrm{s}$, and the DC side voltage contains the fundamental frequency with an even multiple of the low-frequency harmonics on grid side, of which the fundamental frequency of $2 \mathrm{X}$ is the most obvious; the upper and lower side frequencies with high harmonic of integer multiple carrier frequency are included in DC side voltage, of which, 1 and 2 times carrier frequencies are most obvious. 
TABLE I DC side voltage harmonic calculation and simulation results under network voltage imbalance

\begin{tabular}{|c|c|c|c|}
\hline \multirow[t]{2}{*}{ Wind speed } & \multirow{2}{*}{$m, n$, etc. } & \multicolumn{2}{|c|}{ High frequency harmonic } \\
\hline & & Calculated & $\begin{array}{l}\text { Simulation } \\
\text { value }\end{array}$ \\
\hline \multirow[t]{6}{*}{$7 \mathrm{~m} / \mathrm{s}$} & $\mathrm{k}=1 ， \mathrm{~m}=1$ ， & $1950.0 \mathrm{~Hz}$ & $1949.9 \mathrm{~Hz}$ \\
\hline & $\mathrm{n}=0, \mathrm{i}=1$ & & \\
\hline & $\mathrm{k}=1, \mathrm{~m}=1$ & $2050.0 \mathrm{~Hz}$ & $2050.0 \mathrm{~Hz}$ \\
\hline & $\mathrm{n}= \pm 2, \mathrm{i}=1$ & $1850.0 \mathrm{~Hz}$ & $1850.0 \mathrm{~Hz}$ \\
\hline & $k=1 ， m=2 ，$ & $4000.0 \mathrm{~Hz}$ & $4000.0 \mathrm{~Hz}$ \\
\hline & $n= \pm 1, i=1$ & $3900.0 \mathrm{~Hz}$ & $3900.0 \mathrm{~Hz}$ \\
\hline \multirow[t]{6}{*}{$19 \mathrm{~m} / \mathrm{s}$} & $\mathrm{k}=1 ， \mathrm{~m}=1$ ， & $1950.0 \mathrm{~Hz}$ & $1949.8 \mathrm{~Hz}$ \\
\hline & $\mathrm{n}=0, \mathrm{i}=1$ & & \\
\hline & $\mathrm{k}=1, \mathrm{~m}=1$ ， & $2050.0 \mathrm{~Hz}$ & $2050.0 \mathrm{~Hz}$ \\
\hline & $\mathrm{n}= \pm 2, \mathrm{i}=1$ & $1850.0 \mathrm{~Hz}$ & $1850.0 \mathrm{~Hz}$ \\
\hline & $\mathrm{k}=1, \mathrm{~m}=2$ & $4000.0 \mathrm{~Hz}$ & $3999.9 \mathrm{~Hz}$ \\
\hline & $n= \pm 1, i=1$ & $3900.0 \mathrm{~Hz}$ & $3899.8 \mathrm{HZ}$ \\
\hline
\end{tabular}

TABLE II Calculation and simulation results of rotor current harmonics under unbalanced network voltage

\begin{tabular}{|c|c|c|c|}
\hline \multirow[t]{2}{*}{ Wind speed } & \multirow{2}{*}{$\mathrm{m}, \mathrm{n}$, etc. } & \multicolumn{2}{|c|}{ High frequency harmonic } \\
\hline & & Calculated & $\begin{array}{l}\text { Simulatio } \\
\mathrm{n} \text { value }\end{array}$ \\
\hline \multirow[t]{5}{*}{$7 \mathrm{~m} / \mathrm{s}$} & $\begin{array}{ll}k=2, & m=1 \\
n= \pm 2, & i=0\end{array}$ & $2029.2 \mathrm{~Hz}$ & $2030.0 \mathrm{~Hz}$ \\
\hline & $\mathrm{m}=1$ & $2129.2 \mathrm{~Hz}$ & $2130.1 \mathrm{~Hz}$ \\
\hline & $n= \pm 2, i=1$ & $2070.8 \mathrm{~Hz}$ & $2070.3 \mathrm{~Hz}$ \\
\hline & $\mathrm{k}=1, \mathrm{~m}=2$ & $4114.6 \mathrm{H}$ & $4115.0 \mathrm{~Hz}$ \\
\hline & $n= \pm 1, i=1$ & $3914.6 \mathrm{~Hz}$ & $3914.8 \mathrm{~Hz}$ \\
\hline \multirow[t]{6}{*}{$19 \mathrm{~m} / \mathrm{s}$} & $\mathrm{k}=2 ， \mathrm{~m}=1$ & $2031.8 \mathrm{~Hz}$ & $2031.8 \mathrm{~Hz}$ \\
\hline & $\mathrm{n}= \pm 2, \mathrm{i}=0$ & & \\
\hline & $\mathrm{k}=2, \mathrm{~m}=1$ & $2131.8 \mathrm{~Hz}$ & $2132.6 \mathrm{HZ}$ \\
\hline & $\mathrm{n}= \pm 2, \mathrm{i}=1$ & $2068.2 \mathrm{~Hz}$ & $2068.3 \mathrm{~Hz}$ \\
\hline & $\mathrm{k}=1, \mathrm{~m}=2$ & $4115.9 \mathrm{~Hz}$ & $4115.0 \mathrm{~Hz}$ \\
\hline & $\mathrm{n}= \pm 1, \mathrm{i}=1$ & $3884.1 \mathrm{~Hz}$ & $3884.2 \mathrm{~Hz}$ \\
\hline
\end{tabular}




\section{CONCLUSION}

Taking the dual-fed wind power system with grid-tied dual-PWM converters as the research object, this paper conducts a detailed analysis and modeling on the harmonic generation and propagation mechanism in the grid when the three-phase voltage is balanced and unbalanced states. Subsequently, based on RTDS real-time data simulation platform, the double-fed wind turbine model in the grid is built for simulation and verification. In doing so, we draw the following conclusions: a simulation model of the double-fed wind power system, which integrates a grid-connected, voltage-source, back-to-back type dual-PWM converter, is built based on the RTDS real-time data simulation platform. The simulation has captured voltage and current relevant data of the wind power system running in the balance and unbalanced states of grid voltage. The spectrum analysis is also made for these simulation data, which further sheds new light on the accuracy and credibility of theoretical analysis.

This paper focuses more on the harmonic generation and propagation of dual-PWM converters in double-fed wind power system. It is tested by the simulation that the theoretical derivation is more accurate. However, this paper ignores mechanical harmonic sources such as wind turbine gearbox failure, wind shear effect, tower shadow effect and wind speed fluctuation, which will make mechanical velocity and torque generate a series of mechanical harmonics. Therefore, it is imperative to further improve the harmonic modeling theory for the wind power system.

\section{REFERENCES}

[1] Liu, Y., Wang, Z., Li, R., Jiang, X., Sheng, G., Liu, $T$. "Research on the control strategy for grid-side converter of pwm doubly fed induction wind power generators", 2017, 199(1), 012125, DOI: 10.1088/1757-899X/199/1/012125
[2] Ji, X.Q., Liu, G.B., Cheng, L.Y., Li, D. "Power quality simulation of grid-connected doubly fed wind turbine", Advanced Materials Research, 2013, 6, 860-863, DOI: 10.4028/www.scientific.net/AMR.860-863.331

[3] Adam A. "Research On Multi Agent Distributed Application System Based On WWW Platform. Acta Electronica Malaysia, 2020, 4(2), 31-34.

[4] Behnia, H., Faraji, V., Aghasi, M., Arab Khaburi, D. "High- performance doubly fed induction machine drive system using predictive direct torque control drive system fed by indirect matrix converters", International Journal of Numerical Modelling Electronic Networks Devices \& Fields, 2014, 27(1), 34-49, DOI: $10.1002 / \mathrm{jnm} .1888$

[5] Zhu, L.C., He, J., Yang, Y.J., Su, X.Y., Li, F.Y. "Research on dual pwm converter for vscf brushless doubly-fed wind power generator, Applied Mechanics and Materials, 2013, 397-400, 1804-1807, DOI: 10.4028/www.scientific.net/amm.397-400.1804

[6] Moreno A. "Elements Of Music Based On Artificial Intelligence". Acta Informatica Malaysia, 2020, 4(1), 30-32.

[7] Sathishkumar S., Kannan M., Sankarlal R.L. "Thermal Stress Analysis Of Integrated Combustion Engine Piston Using Cae Tools (Aluminum Silicon Alloy, Aluminum Silicon Alloy Steel)". Acta Mechanica Malaysia, 2020, 3(1), 20-23.

[8] Sathiyanarayanan, J.S., Kumar, A.S. "Doubly fed induction generator wind turbines with fuzzy controller: a survey", The Scientific World Journal, 2014, (6), 252645, DOI: 10.1155/2014/252645

[9] Serhoud, H., Benattous, D. "Simulation of grid connection and maximum power point tracking control of brushless doubly-fed generator in wind power system, Frontiers in Energy, 2013, 7(3), 380-387, DOI: $10.1007 / \mathrm{s} 11708-013-0252-\mathrm{z}$ 
[10] Zongze, L., Yu, C., Xudong, Z., Yanrun, H., Gang, W., Yong, K. "Research on the operational principle and control of the nine-switch-converter-based doubly-fed wind generation systems", Zhongguo Dianji Gongcheng Xuebao/proceedings of the Chinese Society of Electrical Engineering, 2015, 35(5), 1221-1228, DOI: 10.13334/j.0258-8013.pcsee.2015.05.024

[11] Rabia, Ali A, Ali S, Sajid A, Zafar A. "A Security Review Over Wi-Fi and Li-Fi". Information Management and Computer Science, 2020, 3(1), 01-09.

[12] Wang, X., Lin, H. "Dc-link current estimation for load-side converter of brushless doubly-fed generator in the current feed-forward control", Iet Power Electronics, 2016, 9(8), 1703-1710, DOI: 10.1049/iet-pel.2015.0910

[13] Pichan, M., Rastegar, H., Monfared, M. "Two fuzzy-based direct power control strategies for doubly-fed induction generators in wind energy conversion systems", Energy, 2013, 51(2), 154-162., DOI: 10.1016/j.energy.2012.12.047
[14] Bekakra, Y., Attous, D.B. "Dfig sliding mode control fed by back-to-back pwm converter with dc-link voltage control for variable speed wind turbine", Frontiers in Energy, 2014, 8(3), 345-354, DOI: $10.1007 / \mathrm{s} 11708-014-0330-\mathrm{x}$

[15] Khan M, Sajid A, Hanif A, Aqib M, Zafar A. "A Review On (Wi-Fi vs. Li-Fi) Technology". Information Management and Computer Science, 2020, 3(1), 10-13.

[16] Bekakra, Y., Attous, D.B. "Direct control of doubly fed induction generator fed by pwm converter with a variable structure control based on a sliding mode control", International Journal of System Assurance Engineering \& Management, 2014, 5(3), 213-218, DOI: $10.1007 / \mathrm{s} 13198-013-0147-8$

[17] Saad, N.H., Sattar, A.A., Mansour, E.A.M. "Low voltage ride through of doubly-fed induction generator connected to the grid using sliding mode control strategy", Renewable Energy, 2015, 80, 583-594, DOI: 10.1016/j.renene.2015.02.054

\section{Creative Commons Attribution License 4.0 (Attribution 4.0 International, CC BY 4.0)}

This article is published under the terms of the Creative Commons Attribution License 4.0

https://creativecommons.org/licenses/by/4.0/deed.en_US 